\title{
Clinical, cytogenetic, and molecular analysis of three families with FRAXE
}

\author{
A J Barnicoat, Q Wang, J Turk, E Green, C G Mathew, G Flynn, V Buckle, M Hirst, \\ K Davies, $M$ Bobrow
}

\begin{abstract}
The probe StB12.3 has been used to screen the FMR-1 gene in 42 pedigrees with a distal Xq fragile site for expansion of the CCG repeat and aberrant methylation of the FRAXA locus. Four families did not have a FRAXA mutation and were investigated further. Fluorescent in situ hybridisation (FISH) and molecular analyses showed that three of these families had an expansion at FRAXE and one at FRAXF. Detailed psychiatric, psychological, and behavioural features of three families with FRAXE identified in the study are presented.
\end{abstract}

All the males who expressed FRAXE had a large methylated CCG repeat at FRAXE. All males with the mutation had some degree of mental handicap. This study illustrates the need for the FRAXE phenotype to be defined further.

(f Med Genet 1997;34:13-17)

Keywords: FRAXE; behavioural phenotype; FRAXF.

\section{Department of Medical and Molecular Genetics, Guy's Hospital, London SE1 9RT, UK \\ A J Barnicoat $Q$ Wang \\ E Green \\ C G Mathew \\ M Bobrow}

Department of Behavioural Sciences, Institute of Child Health, London WC1N 1EH, UK J Turk

Molecular Genetics Group and MRC Haematology Unit, Haematology Molecular Medicine, John Radcliffe Hospital, Oxford OX3 9DW, UK G Flynn V Buckle M Huckle

K Davies

Correspondence to: Dr Barnicoat, Mothercare Department of Clinical Genetics and Fetal Medicine, Institute of Child Health, 30 Guilford Street, London WC1N2EH, UK

Received 24 April 1996 Revised version accepted for publication

25 July 1996 transmitting males.

Some pedigrees without the expansion mutation at FRAXA have a distal fragile site, FRAXE. ${ }^{5}$ The clinical phenotype in pedigrees with fragility distal to FRAXA has not been shown to be related to the presence of the fragile site. ${ }^{67} \mathrm{~A}$ CCG expansion mutation in FRAXE has been identified and early evidence in this report suggests that the phenotype may correlate with the molecular change. ${ }^{8} \mathrm{~A}$ candidate gene for mild mental handicap at the FRAXE fragile site has recently been identified by Chakrabarti et al. ${ }^{9}$ A further fragile site FRAXF has been described in one family identified in this study ${ }^{10}$ and an expansion mutation has recently been reported in this condition also. ${ }^{11} 12$

We have screened 42 pedigrees with a distal $\mathrm{Xq}$ fragile site known to South East Thames Regional Genetics Centre for the FRAXA the mutation was at FRAXE. Clinical, psychological, cytogenetic, and molecular analysis of these three families is presented.

\section{Methods}

PATIENTS

All families known to have a distal $\mathrm{Xq}$ fragile site through previous referral to South East Thames Regional Genetics Centre were contacted for inclusion. The following standardised instruments were used to evaluate psychiatric, psychological, and behavioural disturbance in three of the four families who did not have an expansion mutation in FMR-1: (1) British Ability Scales-short form ${ }^{13}$; (2) Childhood Behavior checklist, Parent Version ${ }^{14}$; (3) Parental account of Childhood Symptoms ${ }^{15}$; (4) Schedule of Handicaps, Behaviour and Skills. ${ }^{16}$

\section{CHROMOSOMAL ANALYSIS}

Two blood cultures were set up from each family member. For one, culture medium contained $300 \mu \mathrm{g} \mathrm{ml}^{-1}$ thymidine as a fragile $\mathrm{X}$ inducer. The second culture in males used low concentration serum (5\%) in medium TC199 and in females used fluorodeoxyuridine $\left(4 \times 10^{-7} \mathrm{~mol} / \mathrm{l}\right)$ as a folate antagonist in standard lymphocyte cultures. Initially, 30 cells were examined from each of the two cultures and the overall background breakage recorded. A further 40 cells for males and 90 cells for females were scored from the culture with the highest background breakage. Positive results were recorded when fragile sites were shown in more than $4 \%$ of cells. mutation, which showed that in three families

\section{DNA ANALYSIS}

Genomic DNA was initially extracted from leucocytes using a salt chloroform method, ${ }^{17}$ but because of recurrent difficulties with incomplete digestion this was later modified to a phenol-chloroform technique. ${ }^{18}$ The FRAXA mutation was analysed by digesting DNA $(8 \mu \mathrm{g})$ with the restriction enzymes EcoRI and EagI (NEB/ Promega). Fully digested DNA samples were electrophoresed, blotted, and hybridised with the radioactively labelled probe StB12.3 as previously described. ${ }^{19}$ DNA from at least one normal male and one normal female control was included in every gel.

The FRAXE mutation was analysed by digestion with HindIII and NotI and the filters were probed with $\mathrm{OxE} 20 .^{20}$ Expansion mut- 
ations were sized by comparison of fragment mobility with a HindIII digest of lambda DNA end labelled with $\left[\alpha^{32} \mathrm{P}\right] \mathrm{dCTP}$.

\section{LOCATION OF THE FRAGILE SITES BY FISH}

Fluorescent in situ hybridisation was carried out with cosmid probes $141 \mathrm{R}$ and VK21 labelled with biotin, previously described by Flynn et $a .^{21}$ The $\mathrm{X}$ chromosome centromere was detected with the DNA probe DXZ1 (Oncor).

\section{Results}

FRAXA FAMILIES

The expansion and aberrant methylation changes were detected in 38 out of 42 pedigrees studied. There were no discrepancies between clinical phenotype, cytogenetic expression, and genotype.

\section{FAMILIES WITHOUT THE FRAXA MUTATION}

Four families were identified who had previously been diagnosed as affected with fragile $\mathrm{X}$ syndrome but who did not show the expansion mutation at FRAXA.

\section{Family $A$}

This is a sibship of three males who all show mild mental handicap and express a fragile site. Their mother (II.1) is illiterate and also expresses a fragile site. III. 1 had an intelligence quotient of 54 with no significant verbal/performance discrepancy. Child behaviour profile indicated functioning in the top $2 \%$ of the population on obsessive-compulsive and hyperactive dimensions. Evaluation by the parents indicated mild concentration difficulties. Mild ritualistic/stereotypic tendencies were shown in a fascination with textures and a resistance to changes in routine.

III. 2 had a developmental quotient of 50 generated using the Vineland scale of social development. Child behaviour profile showed functioning in the top $2 \%$ of the population on the aggression dimension. Teacher ratings confirmed marked classroom inattentiveness. Parental evaluation of attention showed mild concentration difficulties and restlessness with marked impulsiveness. Mildly repetitive speech was noted with ritualistic tendencies in the form of an insistence on routines.

III. 3 had an intelligence quotient of 54 with no significant verbal/performance discrepancy. Child behaviour profile showed no abnormal score. Parental evaluation of attention indicated concentration difficulties and restlessness.

The head circumferences of the affected males were between the 50 th and 75 th centiles. Other family members examined include the maternal grandparents of the affected boys who were clinically and cytogenetically normal. The maternal grandmother was shown to carry the expansion.
Family $B$

This family has only a single affected male (II.1) aged 3.5 years available for study who expresses the fragile site. A developmental quotient of 65 was generated using the Vineland scale of social development. Child behaviour profile showed functioning in the extreme $2 \%$ of the population on multiple dimensions: social withdrawal, depression, immaturity, somatic complaints, schizoidness, and aggression. Parental evaluation of attention showed marked restlessness and fidgetiness and high activity levels. Social impairments were present in the form of gaze aversion, impaired interactive and symbolic play, and impaired imitation of social aspects of pretend play. Speech anomalies consisted of echolalia, repetitive speech, pronominal reversal, and muddling of sequences of words and phrases. Stereotyped repetitive bodily movements coexisted with a preoccupation with repetitive meaningless activities. There was a marked insistence on maintaining the constancy of the environment and routines. The above disabilities are sufficient to qualify for a diagnosis of typical autism.

His mother (I.1), who expresses a fragile site also, shows disturbances of speech and mood typical of females heterozygous for FRAXA. ${ }^{22}$ The affected boy and his mother are not dysmorphic and both have head circumferences greater than the 50th centile.

The proband in this family had a dead maternal uncle (I.4) who had both mental handicap and behavioural problems. A male first cousin of the proband (II.3) has similar clinical features but is unavailable for study.

\section{Family $C$}

This is a sibship of two brothers who express a fragile site. The family presented with III. aged 2.5 years who had language delay. $\mathrm{He}$ had small, simple pinnae and failure to thrive which was attributed to recurrent infections. He required ear reconstruction at 4 years which resulted in a left facial nerve palsy. He has attended mainstream school with additional classroom help, but is currently undergoing a statement of special educational needs aged 10 years. His intelligence quotient was 88 with no significant verbal/performance discrepancy.

Child behaviour profile showed functioning in the extreme $2 \%$ of the population on the following dimensions: obsessive-compulsive, hyperactive, and aggressive. Parental evaluation of attention indicated concentration difficulties with some impulsiveness, marked fidgetiness, and high activity levels. Some delayed echolalia and repetitive speech was present.

His younger brother (III.2) has been investigated for immunological deficiency because of recurrent infections and allergies. A deficiency of an IgG3 subclass was found. Fragile X status was examined because of concerns about his language development. $\mathrm{He}$ is currently in mainstream education with additional help, aged 6 years. Both boys have had middle ear disease and hearing loss which may have contributed to their learning disability. These brothers have head circumferences on the 50th centile. 


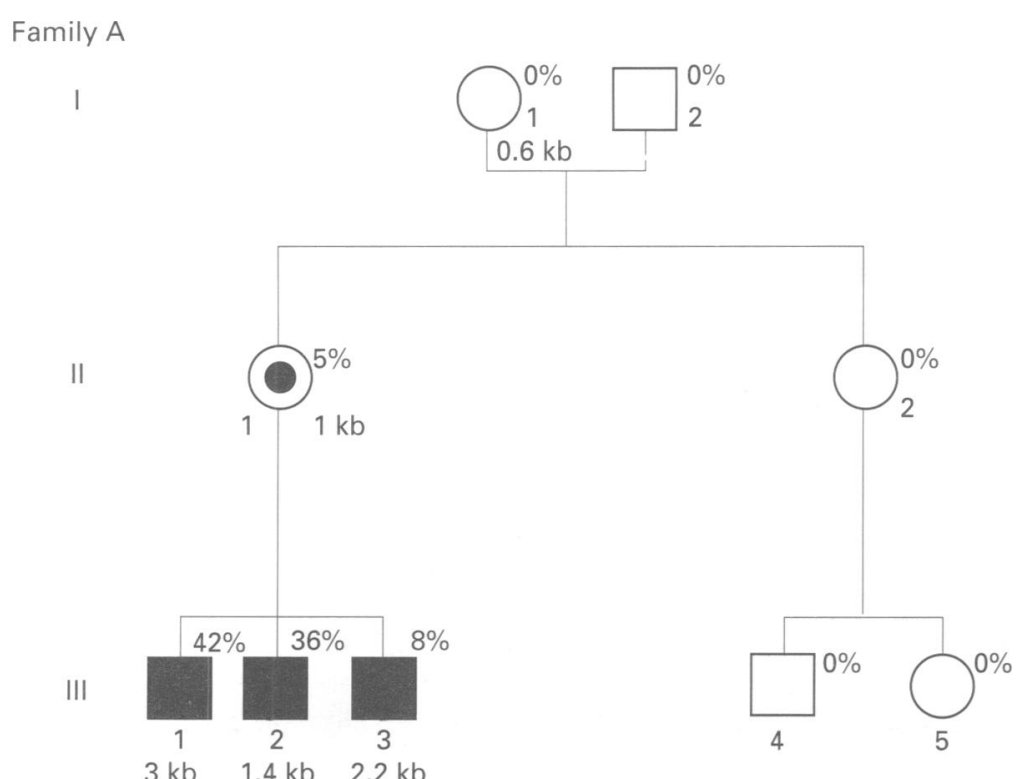

Family B

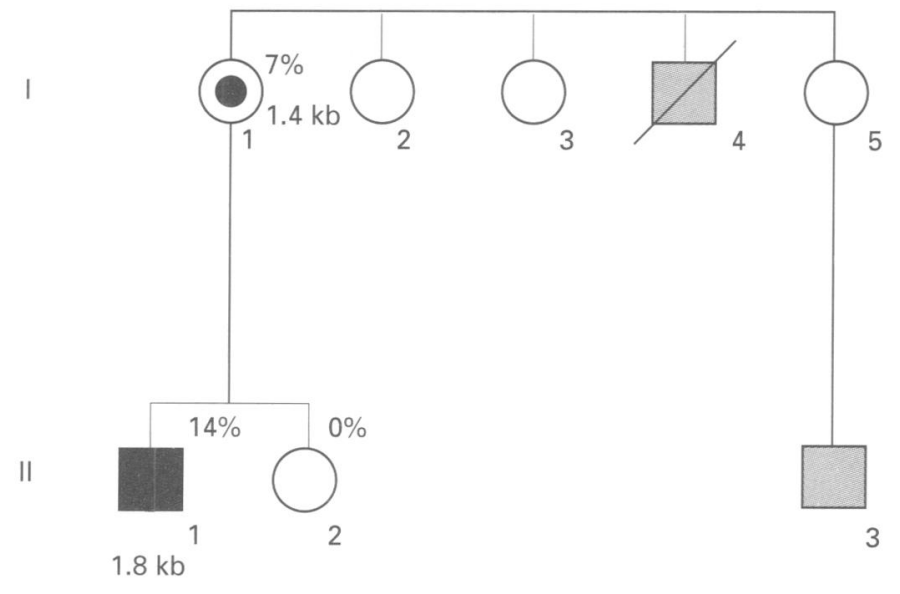

Family C

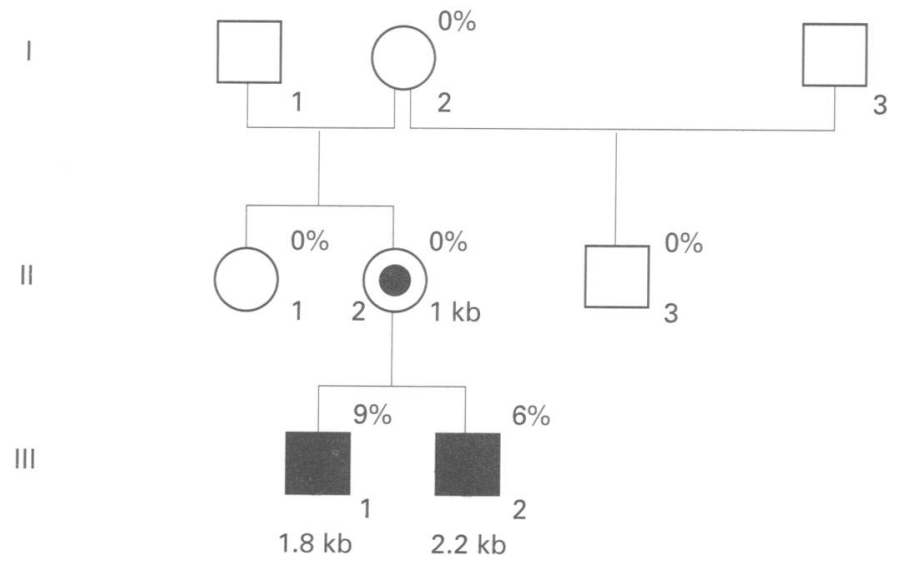

Figure 1 Pedigrees $A, B$, and $C$. Shaded symbols represent subjects with mild mental handicap and hatched symbols represent subjects reported to be affected by family members. Percentages represent the percentage expression of FRAXE in lymphocyte cultures. Sizes of expansion detected at FRAXE are shown in base pairs (Southern blot estimations). who have been examined include the maternal grandmother and uncle. Both are clinically and cytogenetically normal, and without the FRAXE expansion.

IN SITU HYBRIDISATION STUDIES IN FAMILIES A, B, C, AND D

The location of in situ hybridisation signal from cosmid probes E2165 and VK21 confirmed that the fragile site in pedigrees $\mathrm{A}, \mathrm{B}$, and $\mathrm{C}$ is FRAXE. In pedigree $D$ the fragile site was shown by in situ hybridisation to be FRAXF. ${ }^{10}$

MOLECULAR STUDIES FOR FRAXE EXPANSION IN FAMILIES A, B, AND C

The presence and size of the FRAXE expansion shown in family members available for testing is shown in fig 1. A sample blot with results from the families is shown in fig 2 .

\section{Discussion}

This study has highlighted the occurrence of families diagnosed as having fragile $\mathrm{X}$ syndrome before the discovery of the expansion mutation at FRAXA, who have now been shown to have other distal Xq fragile sites with a different phenotype.

Three families with FRAXE are documented in this study. Sutherland and Baker ${ }^{5}$ identified FRAXE by in situ hybridisation, describing two families with a distal fragile site without the expansion at FRAXA; one of their families ${ }^{6}$ has subsequently been shown to have FRAXF rather than FRAXE. ${ }^{11}$ In the two families which they describe the fragile site does not appear to be associated with a clinical phenotype, although in both cases the families were ascertained through a mentally handicapped proband. ${ }^{6}$ The females in these pedigrees have a high level of the fragile site expression in their blood in comparison to that seen in women who carry FRAXA.

Sutherland and Baker ${ }^{5}$ suggested that pedigrees reported by Oberlé et $a l^{4}{ }^{4}$ Nakahori et $a l^{23}$ and Rousseau et al ${ }^{4}$ also have FRAXE. Two further families with FRAXE have been described with mild mental handicap in the probands without facial dysmorphism or macroorchidism. ${ }^{72}$ In these families the expression of the fragile site does not appear to be closely associated with the phenotype.

A report by Hamel et $a l^{25}$ describes the clinical, psychometric, cytogenetic, and molecular data in a large FRAXE pedigree. Mild mental handicap was noted in all affected males and some females with the expansion. No specific phenotypic features were identified in this pedigree, as in those described here.

Mulley et $a l^{26}$ reported six FRAXE pedigrees (including follow up of one of the original pedigrees reported by Sutherland and Baker ${ }^{5}$ ), with further evidence supporting a phenotype of mild mental handicap. One of their pedigrees was ascertained in an unbiased fashion after follow up of a family with FRAXA, and contains three subjects with mild mental impairment who have expansions ranging between 0.5 and
The mother of these boys (II.2) is clinically and cytogenetically normal, although she is shown to carry the expansion. Other relatives 


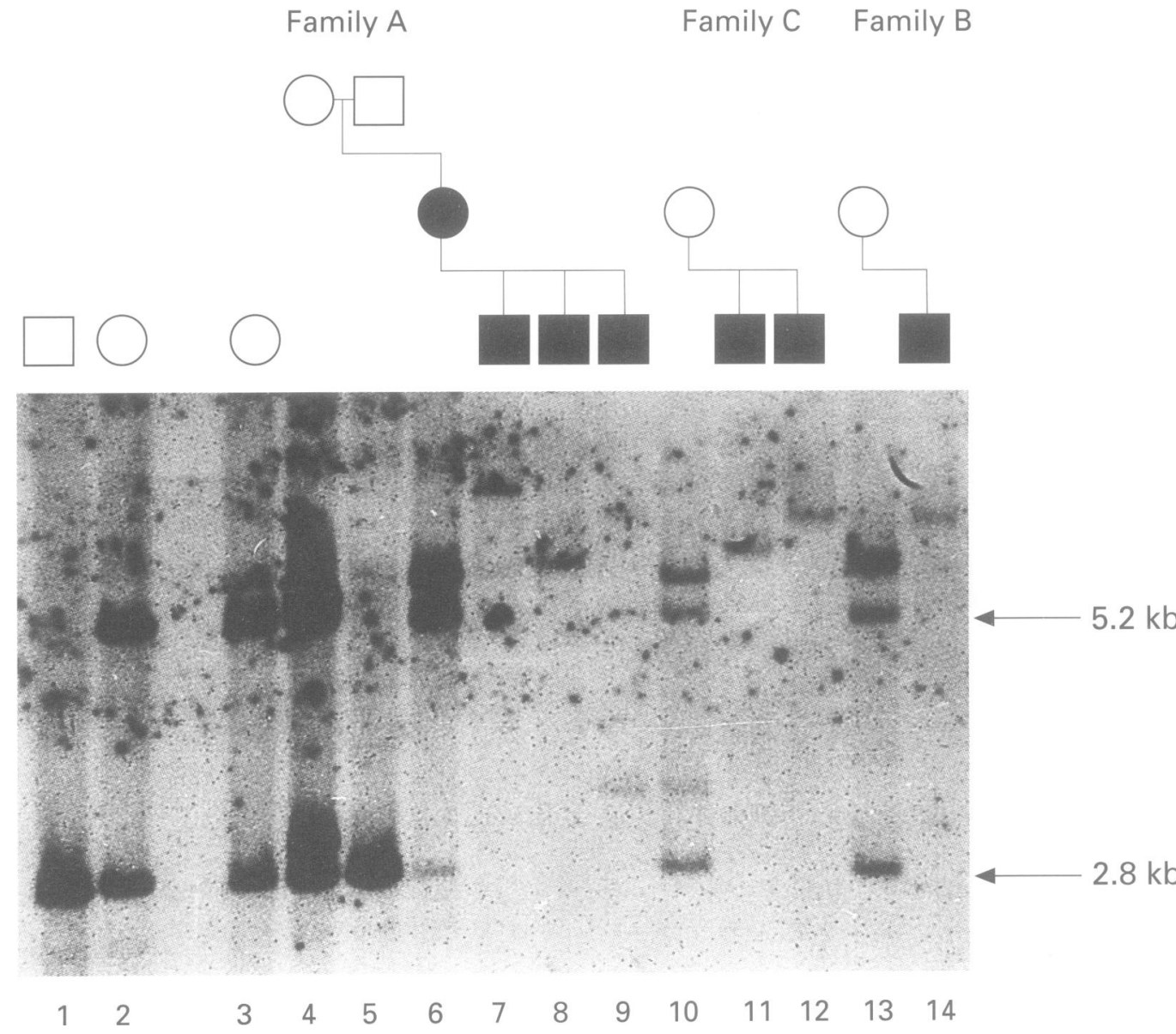

Figure 2 Southern blot analysis of families $A, B$, and $C$. DNA was digested with HindIII and NotI and after electrophoresis and subsequent blotting, the filters were hybridised with the probe OxE 20.

$1.8 \mathrm{~kb}$. In the others there were more handicapped people than would be expected by chance, although in general without other phenotypic abnormalities such as dysmorphic features or behavioural abnormalities.

The clinical features in males with expansions of more than $1 \mathrm{~kb}$ in the three pedigrees with FRAXE reported here have mental impairment without dysmorphic features similar to that documented by Dennis et al, ${ }^{7} \mathrm{Hamel}$ et $a l^{25}$ and Mulley et al. ${ }^{26}$ The pedigree initially reported by Sutherland and Baker ${ }^{5}$ not to show a relationship between phenotype and genotype and later confirmed to have the FRAXE expansion has been subsequently shown to have such a relationship. The families reported here provide confirmatory evidence of a phenotype of mild mental impairment without dysmorphism in FRAXE. Behavioural problems seem rarely to be sufficient to cause social impairment in affected males, and may be no greater than those experienced by males with similar degree of learning disability from any cause.

We have identified $4 / 42(9.5 \%)$ of pedigrees with a distal Xq fragile site as being without an expansion at FRAXA, a similar proportion to that reported by other authors (table 1). Three out of four of the families in this study have FRAXE and in these families there is some evidence for a clinical phenotype associated with the expansion mutation. There
Table 1 Proportion of families with a distal $X q$ fragile site and mental handicap studied who lack the expansion mutation of FMR-1

\begin{tabular}{lllr}
\hline Reference & $\begin{array}{l}\text { Total families } \\
\text { studied }\end{array}$ & $\begin{array}{l}\text { No without } \\
\text { expansion }\end{array}$ & $\%$ \\
\hline This study & 42 & 4 & 9.5 \\
4 & 53 & 4 & 7.5 \\
22 & 68 & 5 & 71.9 \\
27 & 43 & 5 & 1.6 \\
\hline
\end{tabular}

is correlation between expression of FRAXE and clinical features in eight subjects who all have expansions of $1 \mathrm{~kb}$ or more (fig 1 ). Two males can be considered secondary cases (family A, III.3 and family C, III.2); one is mentally handicapped (intelligence quotient 54 ), the other in mainstream education with additional help although without having formal assessment of his intelligence. Two females who are clinically normal and do not express the fragile site are shown to have expansions as well as two females with probable mild manifestations.

Comprehensive psychiatric, psychological, and behavioural evaluation of subjects from these pedigrees showed substantial behavioural heterogeneity. However, the striking observation is that the children showed minimal social impairment, apart from the proband in family B who was sufficiently disabled to fulfil diagnostic criteria for autism. This contrasts 
with the majority of children who have FRAXA who tend to show a number of autistic-like social impairments in the presence of an otherwise friendly and sociable personality. They also show the cluttered litanic speech pattern which was not witnessed in the FRAXE children. ${ }^{28}$ None of the four pedigrees without the expansion at FRAXA conforms to the clinical phenotype seen in fragile $\mathrm{X}$ syndrome when evaluated by formal psychological and behavioural assessments, although because of their developmental delay the initial diagnosis of fragile $\mathrm{X}$ syndrome had not been questioned.

DNA studies for FRAXA mutations are replacing chromosome tests as the diagnostic investigation of choice in some laboratories. Our results suggest that this should be undertaken with caution until there is more information about the clinical phenotype in FRAXE (and FRAXF), unless these expansions are also tested for.

This work was supported by the Waldburg Trust, The Generation Trust, and the Spastics Society. We would like to acknowledge the advice of Professor F Gianelli and Dr A C Berry, and the assistance of Miss D Garrett and the staff of South East Thames Regional Genetics Centre. We thank Dr J-L Mandel for the gift of StB12.3.

1 Sutherland GR, Hecht F. Fragile sites on human chromosomes. Oxford: Oxford University Press, 1985.

2 Sutherland GR. Heritable fragile sites on human chromosomes. I. Factors affecting expression in lymphocyte culture. Am f Hum Genet 1979;31:125-35.

3 Verkerk AJMH, Pieretti A, Sutcliffe JS, et al. Identification of a gene (FMR-1) containing a CGG repeat coincident with a breakpoint cluster region exhibiting length variation in fragile X syndrome. Cell 1991;65:905-14.

4 Oberlé I, Rousseau F, Heitz D, et al. Instability of a 550base pair DNA segment and abnormal methylation in fragile X syndrome. Science 1991;252:1097-102.

5 Sutherland GR, Baker E. Characterisation of a new rare fragile site easily confused with the fragile $\mathrm{X}$. Hum Mol Genet 1992;1:111-13.

6 Romain DR, Chapman CJ. Fragile site at Xq27.3 in a family without mental retardation. Clin Genet 1992;42:33-5.

7 Dennis NR, Curtis G, MacPherson JN, Jacobs PA. Two families with Xq27.3 fragility, no detectable insert in the FMR-1 gene, mild mental impairment and absence of the Martin-Bell phenotype. Am f Med Genet 1992;43:232-6.
8 Knight SJL, Flannery AV, Hirst MC, et al. Trinucleotide repeat amplification and hypermethylation of a $\mathrm{CpG}$ island in FRAXE mental retardation. Cell 1993;74:127-34

9 Chakrabarti L, Knight SJL, Flannery AV, Davies KE. A candidate gene for mild mental handicap at the FRAXE fragile site. Hum Mol Genet 1996;5:275-82.

10 Hirst MC, Barnicoat A, Flynn G, et al. The identification of a third fragile site, FRAXF, in Xq27-28. Hum Mol Genet 1993;2:197-200.

11 Parrish JE, Oostra BE, Verkerk AJMH, et al. Isolation of a repeat showing expansion in FRAXF, a fragile site distal to FRAXA and FRAXE. Nat Genet 1994;8:229-35.

12 Ritchie RJ, Knight SJ, Hirst MC, et al. The cloning of FRAXF: trinucleotide repeat expansion and methylation at a third fragile site in distal Xqter. Hum Mol Genet 1994; 3:2115-21.

13 Elliott CD, Murray DJ, Pearson LS. British Ability Scales, Manuals 1-4. Windsor: NFER-Nelson, 1983.

14 McConaughy SH, Achenbach TM. Practical guide for the Child Behavior Checklist and Related Materials. Burlington VY: University of Vermont Department of Psychiatry, 1988.

15 Thorley G, Taylor E, Schachar RM, et al. Tests of attention and their association with hyperactivity and defiance in child clinic attenders. Unpublished manuscript, 1986.

16 Wing L. The MRC Handicaps, Behaviour and Skills (HBS) Schedule. Acta Psychiatr Scand 1980;62 (suppl 285):241-8.

17 Millenbach R, Lagoda PJL, Walter C. An efficient saltchloroform extraction of DNA from blood and tissues. Trends Genet 1989;5:391.

18 Kunkel LM, Smith KD, Boyer SH, et al. Analysis of human $\mathrm{Y}$ chromosome-specific reiterated DNA in chromosome variants. Proc Natl Acad Sci USA 1977;74:1245-9.

19 Hodgson S, Hart K, Abbs S, et al. Correlation of clinical and deletion data in Duchenne and Becker muscular dystrophy. $\mathcal{f}$ Med Genet 1989;26:682-93.

$20 \mathrm{Knight}$ SJL, Voelckel MA, Hirst MC, et al. Triplet repeat expansion at the FRAXE locus and X-linked mild mental handicap. Am $\mathcal{F}$ Hum Genet 1994;55:81-6.

21 Flynn GA, Hirst MC, Knight SJL, et al. Identification of the FRAXE fragile site in two families ascertained for $\mathrm{X}$ linked mental retardation. $f$ Med Genet 1993;30:97-100.

22 Reiss AL, Hagerman RJ, Vinogradov S, et al. Psychiatric disability in female carriers of the fragile $\mathrm{X}$ chromosome. Arch Gen Psychiatry 188;45:25-30.

23 Nakahori Y, Knight SJL, Holland J, et al. Molecular heterogeneity of the fragile X syndrome. Nucleic Acids Res 1991; 19:4355-9.

24 Rousseau F, Heitz D, Biancalana V, et al. Direct diagnosis by DNA analysis of the fragile $\mathrm{X}$ syndrome of mental retardation. N Engl f Med 1991;325:1673-81.

25 Hamel BCJ, Smits APT, de Graaff E, et al. Segregation of FRAXE in a large family: clinical, psychometric, cytogenetic and molecular data. Am f Hum Genet 1994;55: 923-31.

26 Mulley JC, Yu S, Loesch DZ, et al. FRAXE and mental retardation. $\mathcal{F}$ Med Genet 1995;32:162-9.

27 Mulley JC, Yu S, Gedeon AK, et al. Experience with direct molecular diagnosis of fragile X. $\mathcal{F}$ Med Genet 1992;29: molecular

28 Turk J. The fragile $\mathrm{X}$ syndrome: on the way to a behavioural phenotype. Br f Psychiatry 1992;160:24-35. 